\title{
FRAY LUIS DE LEÓN, APOLOGETA DE TERESA DE JESÚS EN SUS PARATEXTOS
}

\section{LUIS DE LEÓN, APOLOGETTE OF TERESA \\ DE JESÚS IN HIS PARATEXTS}

JAUME GARAU

Universitat de les Illes Balears - IEHM

\section{RESUMEN}

Fray Luis de León fue el primer editor de algunas de las obras de Teresa de Jesús en 1588. En esta edición, redactó una primera Carta dedicatoria publicada al frente de la misma y otra, impresa póstumamente en Roma en 1610 bajo el título de Apología, que fue escrita a raíz de los reparos doctrinales que se cernían sobre la ortodoxia de algunos pasajes de las obras de la santa. En el primero de estos paratextos, el maestro León se esmera en defender la pureza textual de su edición al tiempo que pondera, ya en clave hagiográfica en ambas cartas, la labor reformadora de la santa al amparo del nuevo modelo de santidad que dimana del Concilio de Trento.

Palabras clave: Luis de León, apología, ortodoxia, Teresa de Jesús, paratextos, Trento, santos. 


\section{ABSTRACT}

Fray Luis de León was the first editor of some of the works of Teresa de Jesús in 1588. For this edition, he crafted a Dedicatory Letter published in its preliminary materials, and then another published posthumously in Rome in 1610, with the title Apología. It was written in order to address some of the doctrinal objections that loomed over the orthodoxy of some passages of Saint Theresa's works. In the first of these paratexts, Fray Luis takes great pains to defend the textual purity of his edition, and at the same time ponders, albeit in a hagiographic code in both letters, the reforming labor of the Saint, under the protection offered by the new model of saintliness emanating from the Council of Trent.

Keywords: Luis de León, Apology, Orthodoxy, Teresa de Jesús, Paratexts, Trent, Saints

\section{INTRODUCCIÓN ${ }^{1}$}

Mucho se ha escrito sobre santa Teresa de Jesús (1515-1582), desde diversas perspectivas y con enfoques diferentes. Su figura y obra sigue siendo una fuente constante de temas de investigación que abordan tanto los avatares de su biografía como su rica obra literaria. En su persona se aúnan las líneas de una vida compleja y difícil, con una singularidad literaria poco común con el trasfondo de su imponente labor reformadora.

En esta aportación, nos proponemos estudiar dos paratextos de su obra, singularmente, aquellos que escribió fray Luis de León (1527-1591), primer editor de la santa como se sabe, para la edición príncipe de algunos de sus escritos (Salamanca, Guillermo Foquel, 1588), a los seis años de fallecida la autora, publicados bajo el título de Carta dedicatoria, y la posterior Apología, al poco tiempo de esta publicación, en la que el agustino da respuesta a las críticas negativas que había publicado esta primera edición de varias de las obras de la santa. Esta impresión primera provocó una cuasi inmediata reedición que vio la luz a los pocos meses de la primera (Barcelona, Jaime Cendrat-Gabriel Lloberas, 1589). No consideraremos aquí, por razones evidentes de espacio, las anteriores cartas de san Pedro de Alcántara a santa Teresa, de 14 de abril de 1562; la de san Juan de Ávila, aprobando el libro de la «Vida», de 12 de septiembre de 1568

1 Este artículo resume la conferencia, pronunciada el 23 de mayo de 2019, en el Romanisches Seminar de la Universidad de Heildelberg. 
o la «Aprobación que el maestro fray Domingo Báñez dio del espíritu de santa Teresa y de la relación autobiográfica de su vida», de 7 de julio de 1575, entre otras, pese al gran interés que puedan presentar estas opiniones 'autorizadas'" Tampoco tendremos en cuenta dadas las limitaciones de espacio, y pese a su muy indudable interés, la biografía que le encargó a fray Luis doña Mariana de Austria (1528-1603), en vistas a su beatificación, en tanto que apasionada lectora de Teresa de Jesús, de la que se han conservado 13 hojas manuscritas y que interrumpió la muerte del maestro León en 1591. Debemos observar en este opúsculo, inacabado que, al igual que ocurre en las dos paratextos estudiados, fray Luis trata a Teresa ya como santa con anterioridad a su beatificación en 1614, bajo el pontificado de Paulo V, y a su canonización de 1622, bajo el de Gregorio V.

Sin embargo, debemos reconocer la importancia que revisten en estos escritos los rasgos autobiográficos que deja entrever el agustino en las primeras líneas de este opúsculo póstumo, al confesar al lector que si bien Teresa dio a conocer a sus confesores su espíritu, no reveló, por modestia, muchos de los detalles de su vida que ahora, en el escrito que se presenta, describe León como fruto de su indagación personal sobre la reformadora:

Escribió la parte de ella que fue conveniente para que sus confesores conociesen su espíritu, no la escribió toda, ni dijo muchas cosas por modestia, ni pudo decir las que le sucedieron después de aquella escritura que yo he buscado y he recogido, informándome de sus papeles y de personas de mucho crédito que la trataron y conocieron ${ }^{3}$.

No se ha encarecido suficientemente, creemos, la importancia del paratexto en el marco de la obra literaria en la que se inserta, para influir en los posibles valores que puede presentar para legitimarla, caracterizarla y condicionar, en definitiva, al futuro lector. Tímidamente se han estudiado estos discursos de naturaleza prologal siendo, como son, en algunos casos como los que aquí examinamos, un auténtico tesoro para conocer los textos y autores a los que preceden. En la mente de todos está el estudio, clásico ya, de Alberto Porqueras, del ya

2 Citaremos esta Carta dedicatoria por la edición de Fidel Sebastián Mediavilla que reproduce el texto en su edición de Teresa de Jesús, Libro de la vida (Madrid: Real Academia, MMXIV), 358-368. En adelante, LdV, seguido de la mención de la página. Estos textos aparecen en la edición arriba citada: el de san Pedro de Alcántara (369-370); el de san Juan de Ávila (377-380) y el de fray Domingo Báñez (381$385)$.

3 Obras Completas Castellanas de Fray Luis de León, ed. Félix García (Madrid: BAC, 1957), I, 921. En adelante citaremos OCC, I, seguido de la indicación de la página. Hay edición crítica a cargo de María Jesús Mancho Duque y Juan Miguel Prieto (Salamanca: Universidad, 2015). 
lejano $1968^{4}$, o el más reciente libro coordinado por María Soledad Arredondo, Pierre Civil y Michel Moner ${ }^{5}$ que recoge diversas contribuciones sobre esta desatendida cuestión.

Son, sin duda, estos discursos proemiales elementos importantes que se engarzan en el cuerpo de la obra y, en muchos casos, participan en la generación de su sentido pleno y son, especialmente, en el caso de los que aquí tratamos, por lo que hace a las obras de Teresa de Jesús, discursos en defensa de su obra en tanto que espejo de su vida y, singularmente, valedores de su ortodoxia frente a críticas de signo diverso, como veremos.

\section{ANTECEDENTES. LA CARTA DEDICATORIA}

La Carta dedicatoria de Luis de León a la primera edición de sus obras ha sido objeto de análisis en diversas aportaciones entre las que hay destacar la de Colin P. Thompson, importante estudioso de la obra del agustino, en un trabajo de 1991 en el que bajo el título de raíz frayluisina, "Una elegancia desafeitada", analiza el contenido y estilo de la carta. En esta aportación, Thompson explica que la defensa del estilo de santa Teresa por parte de fray Luis como una muestra de la modernidad de Luis de León, coherente con sus ideas renovadoras sobre la interpretación y traducción de la Biblia.

Hace pocos años, José Manuel Díaz Martín publicó un artículo que, bajo el título "De los Libros de la Madre Teresa a La perfecta casada. La intimidad entre Teresa de Jesús y Luis de León" ", analiza en profundidad estas relaciones. Plantea el autor, con acierto, el que en esta carta Luis de León construye un sermón explicativo en favor de la defensa de las santa a partir de las citas, que podemos ver como constitutivas del tema del sermón tomado del Antiguo y del Nuevo Testamento. Son las siguientes, ya señaladas por el padre Antolín Merino en su edición (1804-1816, Madrid: Imprenta de las hija de Ibarra):

a) "Para juzgar si un hombre ha sido feliz, espera a que muera, que el hombre en sus hijos se conoce" (Eclo., 11, 30)

$4 \quad$ El prólogo en el manierismo y barroco españoles, (Madrid: CSIC, 1968).

5 Paratextos en la literatura española (siglos XV-XVIII), (Madrid, Casa de Velázquez, 2009).

6 “'Una elegancia desafeitada': Fray Luis de León y Santa Teresa”, en San Juan de la Cruz and Fray Luis de León. A commemorative international Symposium, M. Malcom Gaylord, F. Márquez Villanueva (eds.), (Newark (Delaware), 1996), 289-298.

7 Bulletin of Hispanic Studies, 93,9, (2016): 949-962. Debo agradecer al autor su inestimable ayuda al proporcionarme amablemente este artículo. 
b) "Por los frutos, pues, los conoceréis" (Mt., 7,20).

Estos textos cumplen, para Díaz, una función clara al aparecer casi a modo de frontispicio al frente de la carta dedicatoria de la edición príncipe de 1588, a los seis años de fallecer la santa, en un volumen que reunía tres de sus principales libros: el Libro de la vida; Camino de perfección; y el Castillo interior o las Moradas. Y esta función no es otra que, en un momento en el que todavía no estaba afirmada suficientemente la reforma carmelita, sancionarla positivamente al igual que la ortodoxia de su doctrina, objetivo del interés de la Inquisición.

No podemos extendernos aquí sobre esta consideración del texto luisiano visto, como hace por primera vez José Manuel Díaz como sermón, que, aunque singular en su disposición de acuerdo con los usos de la época, lo es también por cuanto desarrolla en sus páginas una intensa, podríamos decir, exposición persuasiva inserta en el armazón retórico, característico del sermón al servicio de la defensa de la vida y obra teresianas, y a partir de lo que podríamos considerar el tema principal que aúna buena parte de su exposición y que no es otro que el de "Por los frutos, pues, los conoceréis" (Mt., 7,20) bajo cuyas palabras late la defensa de la justificación católica de las obras, a partir de una sólida fe en contraste con el lema luterano de Sola Fides ${ }^{8}$. Es conocido que Luis de León era un gran orador de elocuencia persuasiva y penetrante que, sin embargo, adolecía de una voz muy baja, que le dificultaba en gran medida su labor en el púlpito, como afirma el padre Ángel Custodio Vega cuando rebate a Terrones del Caño quien le niega la cualidad de orador ${ }^{9}$.

En el año 2015, Rafael Lazcano había publicado también un interesante artículo en el que, entre otros textos, estudia esta carta dedicatoria ${ }^{10}$. En él, trata de las labores que el agustino desarrolló durante aproximadamente los tres años que dedicó a examinar las obras de la santa en "sus hijas y sus libros". En efecto, desde noviembre de 1586 fray Luis ocupará una parte de su tiempo en

8 Véase en este sentido, entre otros lugares, la declaración del nombre "Camino": "Por manera que este nombre, «camino», demás de lo que significa con propriedad, que es aquello por donde se va a algún lugar sin error, pasa su significación a otras cuatro cosas por semejanza: a la inclinación, a la profesión, a las obras de cada uno, a la ley y preceptos; porque cada una destas cosas encamina al hombre a algún paradero, y el hombre por ellas, como por camino, se endereza a algún fin. Que cierto es que la ley guía, y las obras conducen, y la profesión ordena, y la inclinación lleva cada cual a su cosa.", Luis de León, De los nombres de Cristo, edición, prólogo y notas de Javier San José Lera. Estudio preliminar de Fernando Lázaro Carreter, (Barcelona: Círculo de Lectores, 2008), 71.

9 "Fray Luis de León (El orador)", Historia General de las Literaturas Hispánicas, (Barcelona: Vergara, 1968), II, 590-591.

10 "Fray Luis de León, editor y biógrafo de Teresa de Jesús (1515-1582)", Analecta Augustiniana, LXXVIII, (2015): 77-116. 
imbuirse del espíritu teresiano y del modo de vida de las carmelitas descalzas, convirtiéndose en valedor y paladín de la madre Teresa de Jesús, sus hijas y la reforma del Carmelo ${ }^{11}$ ".

Indica Lazcano que la primera referencia sobre la edición del Libro de la vida proviene de san Juan de la Cruz (1542-1591), al declarar este los conocidos versos, lamentablemente más admirados que leídos, de "Apártalos, amado, / que voy de vuelo", del Cántico espiritual, al afirmar que:

Lugar era este conveniente para tratar las diferencias de raptos y éxtasis y otros arrobamientos y sutiles vuelos de espíritu que a los espirituales suelen acaecer. Mas porque mi intento no es sino declarar brevemente estas canciones, como en el prólogo prometí, quedarse han para quien mejor sepa tratar que yo, y porque también la bienaventurada Teresa de Jesús, nuestra madre, dejó escritas de estas cosas de espíritu admirablemente, las cuales espero en Dios saldrán presto impresas a luz ${ }^{12}$.

Es muy importante tener en cuenta que, según datos que aporta Lazcano, que el "primero de septiembre, reunido el definitorio de los Carmelitas descalzos en Madrid, del que formaba parte Juan de la Cruz, aprueba la edición de los «libros de la Santa» ${ }^{13}$ ", al tiempo que se encomienda a Ana de Jesús, priora del convento de Santa Ana de Madrid, que, en palabras del cronista de la Historia del Carmen Descalzo, Jerónimo de San José:

procurase cobrar el Libro original de la Vida de la Santa, que todavía estaba en la Inquisición, y también recoger los demás en orden a que se imprimiesen juntos...La Inquisición dio con mucho gusto el Libro que tenía, y recogidos otros dos; es a saber, el de Camino de perfección, y las Moradas, con algunos otros papeles sueltos se presentaron todos al Consejo Supremo de Castilla, el cual lo remitió al muy reverendo y doctísimo Padre Fray Luis de León, de la Orden de San Agustín, Catedrático de Prima de Escritura de la Universidad de Salamanca, y uno de los más insignes en todas las letras y erudición, que ha tenido aquella Orden sagrada ${ }^{14}$.

Parece claro, pues, que se encarga a fray Luis la edición de algunas obras de Teresa de Jesús que se hallan en poder de la Inquisición, institución que examina su ortodoxia y que no tiene objeción alguna en ceder los originales a la priora una vez que esta se considera probada, y al amparo de la decisión tomada

11 Lazcano, "Fray Luis de León, editor y biógrafo de Teresa de Jesús...", 80.

12 Lazcano, "Fray Luis de León, editor y biógrafo de Teresa de Jesús...", 80.

13 Lazcano, "Fray Luis de León, editor y biógrafo de Teresa de Jesús...", 82.

14 Lazcano, "Fray Luis de León, editor y biógrafo de Teresa de Jesús...", 82. 
por el definitorio de los Carmelitas descalzos de Madrid. El encargo de preparar la edición a fray Luis no deja lugar a dudas, en los encarecimientos del cronista de la orden del Carmen Descalzo, sobre la excelencia que se esperaba al preparar el agustino esta edición primera.

Examina Lazcano los manuscritos utilizados por fray Luis para preparar su edición y todo el proceso editorial posterior, en un análisis pormenorizado de los mismos durante casi un año mientras residía fray Luis en Madrid, en el convento de San Felipe el Real, en 1587. Sorprende al lector moderno el propósito de 'mantener la pureza del texto', como diríamos hoy. Fray Luis enfatiza que los textos de Teresa de Jesús los edita "sin mudarlos" ni en palabras ni en cosas, de que se habían apartado mucho los traslados que andaban, o por descuido de los escribientes o por atrevimiento y error. Que hacer mudanza en las cosas que escribió un pecho en quien Dios vivía y que se presume le movía a escribirlas, fue atrevimiento grandísimo, y error muy feo querer enmendar las palabras; porque si entendieran bien castellano, vieran que el de la madre es la misma elegancia"(LdV, 363).

No hay duda ninguna de la calidad de los trabajos que acabamos de mencionar en relación a la Carta dedicatoria de la primera edición. Sin embargo, no conocemos estudio alguno relativo al segundo de los paratextos que consideramos aquí ${ }^{15}$, publicado póstumamente, en el libro de fray Tomás de Jesús, Compendio de los grados de oración (Roma, 1610) bajo el título de Apología, como consecuencia de las dudas que se cernían sobre la ortodoxia de algunos pasajes de las obras de la santa.

En ambas cartas, Luis de León se propone defender la ortodoxia doctrinal de Teresa frente a sus detractores, en un momento inicial de la reforma teresiana, y antes de su proceso de canonización, pese a que el maestro León ya la presenta como santa, como ya hemos dicho, siguiendo un modelo de santidad que ya podríamos considerar plenamente tridentino, según intentaremos probar más adelante.

Como sabemos, Teresa de Jesús fue sospechosa de estar influida por el iluminismo, por una Inquisición que interpretaba este movimiento como una manifestación en España del luteranismo. Su figura suscitaba inquietud por diferentes razones que han sido cumplidamente estudiadas: por el hecho de ser mujer; por su práctica de la oración mental unida a la de la de la contemplación;

15 Cuando este artículo ya estaba escrito, apareció la interesante aportación de Javier San José Lera, "Fray Luis de León y Teresa de Jesús: encuentros en el libro", Lectura y Signo (2020): 163-188, en el que estudia, especialmente, el primero de estos paratextos. 
por su carencia de estudios de Teología y, especialmente, por sus revelaciones y éxtasis, sin contar, por supuesto, con el agravante de los recelos de las otras órdenes que no veían con buenos ojos su ingente labor reformadora y fundacional ${ }^{16}$. De entre las distintas denuncias de las que fue víctima hay que resaltar la de la princesa de Éboli sobre el Libro de la vida, que ella había tenido ocasión de consultar, tras múltiples ruegos a la santa para que se lo prestase.

Veamos, pues, cuáles son los aspectos que enfatiza fray Luis en su defensa y presentación de la ortodoxia de las obras de Teresa de Jesús.

Comienza la carta dedicatoria con la afirmación de no haber conocido a la reformadora en vida:

Yo no conocí ni vi a la madre Teresa de Jesús mientras estuvo en la Tierra, mas ahora que vive en el Cielo la conozco y veo casi siempre en dos imágenes vivas que nos dejó de sí, que son sus hijas y sus libros, que a mi juicio son también testigos fieles, y mayores de toda excepción, de grande virtud. Porque las figuras de su rostro, si las viera, mostráranme su cuerpo; y sus palabras, si las oyera, me declararan algo de la virtud de su alma; y lo primero era común, y lo segundo sujeto a engaño, de que carecen estas dos cosas en que la veo ahora. Que, como el Sabio dice, el hombre en sus hijos se conoce. Porque los frutos de cada uno deja de sí cuando falta, esos son el verdadero testigo de su vida; y por tal le tiene Cristo cuando en el Evangelio, para diferenciar al malo del bueno, nos remite solamente a sus frutos: De sus frutos, dice, los conoceréis (LdV, 358).

La obra de Teresa se refleja en sus obras y en sus libros, en "sus hijas y sus libros", como escribe. Establece, pues, Luis de León un diálogo con Teresa de Jesús a través de sus libros y mediante el ejemplo vivo de su labor reformadora que acreditan sus hijas en religión. La referencia escrituraria a Salomón de que el hombre en sus hijos se conoce (Eclo. 11,30), alude a estas en tanto que resultado de su reforma del Carmelo; y del mismo modo, remata este pasaje con la conocida cita de Mateo 7,20, relativa a la importancia de las obras.

Obviamente, estas dos referencias que actúan en la carta a modo de tema doble del sermón, como ya hemos dicho que lo califica, acertadamente, José Manuel Díaz, vertebrarán y otorgarán el sentido pleno a todo el texto, en cuanto que la cita del Eclesiástico se refuerza en la de san Mateo, para afirmar con contundencia el valor de las obras en la vida de la santa y, en consonancia,

16 Véase de Fidel Sebastián Mediavilla, entre otros, «Teresa de Jesús y la Inquisición», en su edición del LdV, pp. 432-435. 
muestran la importancia que otorga el catolicismo a las obras para la justificación del cristiano, frente a la tesis teológicas protestantes del valor de la fe que encarna el lema de Lutero Sola Fides. Estamos, pues, ante el comienzo de un discurso en el que el catedrático de Salamanca explicita claramente su defensa de Teresa en su tiempo, y ante los reparos de heterodoxia de los que había sido víctima, desde distintos ángulos.

En efecto, Teresa de Jesús es ya para fray Luis una mujer que goza de la santidad en el cielo y es, sobre todo, un modelo de virtud y actuación que pervive en los frutos de su reforma del Carmelo en la tierra, presentada como un milagro que anticipa y predispone a su canonización, pese a quienes durante su vida dudaron de sus revelaciones y éxtasis:

Así que la virtud y santidad de la madre Teresa, que viéndola a ella me podría ser dudosa e incierta, esa misma ahora no viéndola, y viendo sus libros, y las obras de sus manos que son sus hijas, tengo por cierta y muy clara. Porque, por la virtud que en todas resplandece, se conoce sin engaño la mucha gracia que puso Dios en la que hizo para madre de este nuevo milagro, que por tal debe ser tenido lo que en ellas Dios ahora hace, y por ellas $(\mathrm{LdV}, 358)^{17}$.

En relación, a la naturaleza portentosa de Teresa de Jesús, hay que recordar que será el propio fray Luis quien recuerde la etimología de 'Teresa', nombre guiado por el propio Dios, según explica en el opúsculo inacabado que redactó por encargo de la hermana de Felipe II, María de Austria (1528-1603), al afirmar que "Teresa es Tarasia, nombre antiguo de mujeres, y griego, que quiere decir milagrosa"(OCC,I, 922).

Juzga, en esta línea, como un hecho milagroso el que Teresa, siendo mujer enseñase y fuera capaz de emprender la reforma que ahora contempla en las monjas de su orden. Es, para el maestro salmantino, Teresa mujer campeona de la fe católica frente a los peligros de la herejía a la que hace frente con el conjunto de su obra:

quiso Dios en este tiempo-escribe fray Luis-cuando parece triunfa el demonio en la muchedumbre de los infieles que le siguen y en la porfía de tantos pueblos herejes que hacen sus partes, y en los muchos vicios de los fieles que son de su bando, para envilecerle y para hacer burla de él, ponerle delante, no un hombre valiente rodeado de letras, sino una pobre mujer que le desafiase y

17 Ya Domingo Báñez, en la Aprobación del Libro de la vida, había manifestado que "esta mujer, a lo que muestra su relación, aunque ella se engañase en algo, a lo menos no es engañadora, porque habla tan llanamente, bueno y malo, y con tanta gana de acertar, que no deja dudar de su buena intención" (LdV, 382). 
levantase bandera contra él, e hiciese públicamente gente que le venza y acocee, quiso (sin duda para demostración de lo mucho que puede) en esta edad adonde tantos millares de hombres, unos con sus errados ingenios y otros con sus perdidas costumbres aportillan su reino, que una mujer alumbrase los entendimientos y ordenase las costumbres de muchos, que cada día crecen, para reparar estas quiebras $(\mathrm{LdV}, 359)$.

Bajo el uso de voces y referencias a la milicia, tan propios por otra parte de la predicación de la época bajo los que subyace el concepto paulino del miles Cristi, Teresa de Jesús lucha contra la herejía y enseña a los hombres el camino que estima de la verdad católica.

Poco después, se hace eco Luis de León de la pretensión protestante que toma como argumento de sus planteamientos teológicos el retorno a una iglesia primitiva, de la que este movimiento considera que se ha alejado la iglesia romana. Su argumentación es, frente a estos, que la gracia que se estima que es consustancial a la Iglesia católica, pese a la madurez de los tiempos en los que ha pervivido, revive también en la figura de una mujer, y, al igual o casi igual que en los tiempos apostólicos, y como contrapartida a las pretensiones protestantes de encarnar su reforma la auténtica iglesia primitiva, mantiene en Teresa de Jesús está pureza original. Obsérvese, en la transcripción que sigue la alusión al linaje 'más flaco', probable reminiscencia al carácter converso de la santa, y del propio fray Luis:

Y en esta vejez de la Iglesia tuvo por bien de mostrarnos que no se envejece su gracia, ni es ahora menos virtud de su espíritu, que fue en los primeros y felices tiempos de ella, pues, con medios más flacos en linaje que entonces, hace lo mismo, o casi lo mismo que entonces.

Porque (y este es el segundo milagro) la vida en que vuestras reverencias viven, y la perfección en que las puso su madre, ¿qué es sino un retrato de la santidad de la Iglesia primera? (LdV, 359).

Delicadamente el maestro León vuelve a referirse en la carta dedicatoria, poco después, a la cuestión de la honra, que no preocupa, como nos dirá, a las hijas de Teresa en un alegato en contra de la discriminación que sufrían los conversos y en la idea de que Dios no le expurga el linaje a nadie, como sí ocurría con la información genealógica a la que era preceptivo someterse para ingresar en determinadas órdenes o cargos de algunas iglesias. Recuérdese, en este sentido, que Teresa de Jesús no introdujo estatuto de limpieza alguno en las reglas de su orden reformada: 
y llegan con las obras -escribe- donde en razón de perfecta vida y de heroica virtud apenas llegaron con la imaginación los ingenios. Porque huellan riquezas y tienen en odio la libertad, y desprecian la honra, y aman la humildad y el trabajo (LdV, 360).

Laten bajo estas palabras de desprecio de la honra, como decimos, la denuncia de la discriminación social que comportaba la desigualdad de linajes, y en su caso legal bajo la figura de los estatutos de limpieza. Fray Luis ya la había denunciado pocos años antes, en 1585, en De los nombres de Cristo, cuando trataba del de «Rey de Dios» que, con el tiempo, motivó desaprobaciones diversas de autores que veían en el texto una censura solapada a la Inquisición, como ya señaló en su día Bataillon al comentar estas censuras en su Erasmo y España ${ }^{18}$. El maestro Luis había escrito que

No es posible que se anude con paz el reino cuyas partes están tan opuestas entre sí y tan diferenciadas, unas con mucha honra y otras con señalada afrenta. Y como el cuerpo que en sus partes está maltratado y cuyos humores se conciertan mal entre sí, está muy ocasionado y muy vecino a la enfermedad y a la muerte, así, por la misma manera el reino adonde muchas órdenes y suertes de hombres y muchas casas particulares están como sentidas y heridas, y adonde la diferencia, que por esta causa pone la fortuna y las leyes, no permite que se mezclen y se concierten bien unas con otras, está sujeto a enfermar y a venir a las armas con cualquiera razón que se ofrece ${ }^{19}$.

Procura fray Luis que la obra de Teresa de Jesús sea tenida por inflamada del propio Espíritu, como manifestará, con lo que presenta una brillante patente de ortodoxia católica. Enlaza, en su glosa de la obra teresiana, la inspiración divina con la singular belleza de su prosa:

Y no es menos clara ni menos milagrosa la segunda que dije, que son las escrituras y libros, en los cuales sin ninguna duda quiso el Espíritu Santo que la madre Teresa fuese un ejemplo rarísimo; porque, en la alteza de las cosas que trata y en la delicadeza y claridad con que las trata, excede a muchos ingenios; y en la forma y en el decir y en la pureza y facilidad del estilo, y en

18 Erasmo y España (Madrid: Fondo de Cultura Económica, 1986): 767 n.. Cristóbal Cuevas, en su edición de De los nombres de Cristo (Madrid: Cátedra, 1977): 377n., se hará eco de esta nota, complementándola con la postura del Zabaleta en las páginas que le dedica en "El linajudo", de El día de fiesta por la mañana (1654), obra que había editado modernamente (1983). Zabaleta es heredero de una tradición de autores que defendían radicalmente los estatutos de limpieza que había introducido el cardenal Juan Martínez Silíceo en la catedral de Toledo, en 1547, y entre los que se cuentan, entre otros, el propio Quevedo y su amigo, el humanista y gramático, Bartolomé Jiménez Patón.

19 Luis de León, De los nombres de Cristo, 219. 
la gracia y buena compostura de las palabras, en la elegancia desafeitada que deleita en extremo, dudo yo que haya en nuestra lengua escritura que con ellos se iguale. [...] y no dudo sino que hablaba el Espíritu Santo en ella en muchos lugares, y que le regía la pluma y la mano, que así lo manifiesta la luz que pone en las cosas oscuras, y el fuego que enciende con sus palabras en el corazón que las lee ( $\mathrm{LdV}, 361)$.

\section{LA APOLOGÍA}

En 1610, en las prensas de Iacomo Mascardo, apareció en Roma la obra de Tomás de Jesús Suma y compendio de los grados de oración ${ }^{20}$ en la que se publicó, bajo el título de Apología, la segunda de las cartas dedicatorias escritas por Luis de León que analizamos en esta aportación. El padre Félix García, en la edición que seguimos de las Obras Completas Castellanas del agustino, al parecer no tuvo en cuenta esta primera edición romana del Compendio, ya que señala su aparición en Madrid (Madrid: Luis Sánchez, 1615)²1.

La, como se titula, "Apología del padre Maestro fray Luis de León, Catedrático de Escritura de la Universidad de Salamanca", ocupa (los preliminares están sin paginar) las pp. [19-25] de esta edición póstuma. Al título le sigue un subtítulo que, probablemente, fuera del propio editor de la obra, Tomás de Jesús, y no de fray Luis, así lo parece anunciar el padre García al situar entre corchetes este subtítulo. Dice así: "Donde muestra la utilidad que se sigue a la Iglesia, en que las Obras de la beata madre Teresa de Jesús, y otras semejantes anden impresas en la lengua vulgar" (OCC, I, 915).

Probable alusión a las prevenciones que se tenían en relación a la lectura de la Biblia en lengua vulgar, por cuanto estas lecturas derivaban en interpretaciones doctrinales poco ortodoxas. Del mismo modo, se consideraba que la obra de la santa podía dar lugar a estos desvíos.

Justifica fray Luis su Apología a raíz del éxito de la primera edición de su obra en 1588. Esta edición motivó las críticas del dominico Alonso de la Fuente $^{22}$ contra la obra de Teresa, denunciándola ante la Inquisición, implicando

21 OCC, I, $915 \mathrm{n}$..

22 Lazcano, "Fray Luis de León, editor y biógrafo de Teresa de Jesús...", p. 98 n.. 
incluso a fray Luis, aunque sin respuesta por parte de este severo tribunal. A causa de este y otros comentarios, redactó la Apología que nos ocupa.

Estamos ante un texto muy bien estructurado. En el primer párrafo, presenta Luis de León el objeto de su escritura y anuncia que responderá con brevedad a todos los reparos a la obra de Teresa de Jesús. Hay que señalar, como así lo hace el padre García, en la edición que seguimos, recordando al padre $\mathrm{Merino}^{23}$, que el maestro León denomina ya como santa a Teresa, tiempo antes de ser canonizada, como ya hemos visto en la Carta dedicatoria de la primera edición.

Ya al comienzo del texto, Luis de León se presenta como valiente defensor de la obra de Teresa y se propone exponer las razones que le guían para luchar contra los reparos doctrinales que "algunos, según he oído -escribe-, por no saber más, o por parecer que saben, o por respetos de emulación, han hablado menos bien que debían" (OCC, I, 915).

Comienza pues, su Apología, con la voluntad de clarificar la doctrina de la que, con el tiempo fuera proclamada santa y Doctora Universal de la Iglesia, y que en estos momentos primeros de la difusión de su obra se halla bajo la sombra de la sospecha de heterodoxia. No debemos olvidar que, ya en el primer texto de presentación a la edición de algunas de sus obras, Luis de León se había esmerado, como hemos visto, en defender a Teresa de Jesús como modelo a tener en cuenta por lo que hace a su plena comunión doctrinal con la Iglesia, procurando, en buena medida, mostrarnos una figura ejemplar de santidad típicamente tridentina, alejado, por tanto, de los excesos hagiográficos que eran tan comunes hasta el momento del Concilio y que él, en tanto que discípulo de Melchor Cano, pudo conocer de primera mano, como trataremos a continuación.

Tales prevenciones sobre las experiencias místicas de Teresa de Jesús deben entenderse en el contexto de la represión del iluminismo en la España de su tiempo que comportaron, en buena medida, el cuestionamiento de la memoria de Teresa de Jesús y de su obra, como muy bien estudió Vicente Beltrán de Heredia en sus importantes estudios "Un grupo de visionarios y pseudoprofetas durante los últimos años de Felipe II", ampliado, al también de un tituló tan parecido como "Un grupo de visionarios y pseudoprofetas durante los últimos años de Felipe II y repercusión de ello sobre la memoria de Santa Teresa" ${ }^{24}$. En efecto, durante los años en los que se publica y escribe Luis de León estas cartas dedicatorias se producen diversos procesos, llevados a cabo por la Inquisición de Toledo entre los años de 1587 y 1596, en los que se someten casos de

24 Publicados en Revista Española de Teología, VIII, 1947, pp. 373-397 y 483-534. 
visionarios, algunos incluso fueron encomendados al dictamen de Luis de León, sin que este en todos ellos valorara inspiración divina alguna. Estos, sin duda, tendieron a oscurecer la memoria de la santa, muy a su pesar.

En efecto, ya al comienzo de la Apología se apresta a mencionar, a modo de introducción, cuáles son los aspectos de su obra puestos en cuestión ya que

cuanto a la verdad de la doctrina, no sé qué hayan puesto en falta; sólo ponen inconveniente en su licción por tres títulos y razones. Una, porque enseñan la oración que llaman de unión, que dicen no es bien enseñarla, y no dicen por qué. Otra, porque tienen algunas cosas escuras para ser entendidas generalmente de todos. La tercera, porque la santa Madre Teresa cuenta en ellos muchas revelaciones que tuvo. A que responderé con brevedad (OCC, I, 915).

En la búsqueda de la verdad, que preside toda la argumentación frayluisiana de este escrito apologético, defiende el porqué, contrariamente al parecer de sus detractores. Es importante dar a conocer la oración que llaman de 'unión', fundamentada en la conclusión máxima de la mística entendida, en su culminación, como fusión con la divinidad por la gracia del Señor, como la define:

oración de unión es una suspensión del alma en Dios, que acaece cuando estando uno orando y discurriendo con el entendimiento, Dios, aplicando su luz y su fuerza, le allega a Sí y le suspende el discurrir del entendimiento, y le enciende la voluntad con un amor unitivo (OCC, I, 915).

Justifica este estado unitivo de Teresa señalando la tradición existente en la Sagrada Escritura de raptos y éxtasis que allí se atestiguan. Es, además en su parecer, necesario que

haya libros que traten de él, y que declaren su naturaleza y sus pasos. ¿En qué cabe condenar un libro malo, porque es guía de un camino bueno? Porque si conviene que no se escriba, será porque conviene que no se sepa; y si esto conviene, será porque es bien que no se use; lo cual ninguno será tan tonto o ignorante que lo ose decir. Por donde, al revés, pues es útil su uso, es necesaria su ciencia; y por la misma razón provechoso escribirla (OCC, I, 916).

Frente al segundo reparo, importante en la obra de Teresa de Jesús, el relativo a la dificultad de comprensión de sus textos por muchos, su 'escuridad' como la denomina, argumenta que si fuera por esta dificultad de inteligencia de los textos habría que proceder del mismo modo con todos, singularmente con los grandes autores de la Teología desde san Agustín a Escoto o Durando, entre otros que menciona. Para fray Luis, el sentido está al servicio del espíritu y este trasciende a la mera forma gramatical que, en tanto que simple signo fonético, 
nos trasporta al concepto de lo inefable ${ }^{25}$. Pero, aun en este caso, sostiene el agustino que la prosa teresiana suscita, incluso en quien no la entiende o vislumbra su significación, mucho provecho:

lo escuro de estos libros, que es poco, no daña a nadie y aprovecha a muchos; porque quien lo entiende, saca provecho de ello, y quien no, ni daño ni provecho. Y digo mal, que aun quien no lo entiende saca provecho; porque esta escuridad no está en las palabras, sino en algunas de las cosas; que quien no tiene de ellas experiencia, no las sabe comprender. Y lo que de esta manera no se entiende, ordinariamente cría admiración y deseo de su experiencia, que son cosas de mucho provecho (OCC, I, 917).

El reparo tercero hace referencia a las 'revelaciones' que recibió Teresa de Jesús que se habían considerado de dudosa veracidad, lo que determinaría el poner en duda sus virtudes extraordinarias y, por ende, la santidad que pretende dibujar Luis de León en esta apología. Quienes dudan de ello se oponen a la difusión de los hechos portentosos que muestran tales revelaciones. Contrariamente, defiende León su difusión siguiendo la tradición de la Iglesia ya que

En los libros sagrados hay muchas; en las historias eclesiásticas muchas más; en las vidas de los santos sin número. Vean las historias de la Orden de San Francisco, de Santo Domingo, de San Agustín y de otras Órdenes, que tienen más revelaciones que hojas (OCC, I, 918).

La defensa de lo portentoso, reflejado en la obra de la futura santa de la Iglesia, se equipara, como mínimo, con la hagiografía tradicional porque tanto en los relatos de aquella como en la ingente obra de esta puede existir la falsedad de lo narrado:

Mas de la lección, dicen, nace el deseo. Si nace, bórrense los libros sagrados; quémense las historias eclesiásticas; rómpanse los Flos Sanctorum, las vidas de santos, los Diálogos de San Gregorio; las relaciones de los que fundaron y multiplicaron las Órdenes. Engañada ha estado la Iglesia, que hasta agora ha escrito y querido que se lea lo que abre la puerta al demonio (OCC, I, 918).

Contra los difamadores de la obra teresiana, clama Luis de León en la parte final de su Apología, en el sentido de poner en duda vivamente la autoridad moral de quienes la cuestionan:

25 De ahí su afirmación de que en el nombre "lo que dice la boca es señal de lo que se entiende en el alma. Y así, no es posible que llegue la palabra adonde el entendimiento no llega." ( "De los nombres en general", en De los nombres de Cristo, 34). 
Si porque no quieren que sea tan santa la Madre Teresa, no son ellos los que reparten la santidad; bien puede haber santos que ellos no conozcan, y, aunque ellos no quieran, fue santa y muy santa (OCC, I, 919).

Es, en el parecer de fray Luis, el espíritu del mal quien inspira el comentario de los detractores de Teresa de Jesús que, si bien, dudan de sus revelaciones, condenan la 'escuridad' de sus textos, o el carácter unitivo de sus raptos.Están dominados por el Maligno ya que son ciegos ante la grandeza que se manifiesta en estos tres ámbitos en la obra de la santa y, como es tópico habitual en muchos escritos ascéticos de la época, les recrimina el no condenar la mucha prosa de ficción de su tiempo, encabezada por La Celestina o los libros de caballerías:

$\mathrm{Y}$ ansi concluyo diciendo que tengo por sin duda que trae el demonio engañados a los que de estos Libros no hablan con la reverencia que deben; y que sin duda los menea la lengua, para, si pudiese por su medio, estorbar el provecho que hacen. Y vese claramente por esto: porque si se movieran con espíritu de Dios, primero y ante todas cosas, condenaran los libros de Celestina, los de caballerías y otras mil prosas y obras llenas de vanidades y lascivias, con que cada momento se emponzoñan las almas. Mas como no es Dios mismo quien los mueve, callan esto, que corrompe la cristiandad y costumbres, y hablan de lo que ordena y recoge, y lleva a Dios con eficacia grandísima. (OCC, I, 920).

\section{EN LA ESTELA DE TRENTO}

No podemos concluir este estudio, a pesar de no haber explorado en su totalidad ambas cartas dedicatorias, sin abordar el modo en el que el maestro León pondera las cualidades que adornan la santidad de Teresa de Jesús,y que pueden ser consideradas ya típicamente tridentinas ${ }^{26}$ en el sentido de evitar el relato legendario, y exageradamente falso, como denunciaba Melchor Cano, su compañero en la Escuela de Salamanca, a la vez que antiguo profesor de Luis de León, en De los lugares teológicos, importante obra publicada en Salamanca en 1563, en el mismo año de conclusión del Concilio de Trento, al denunciar que Laercio

escribió las Vidas de los filósofos con mayor rigurosidad que los cristianos las vidas de los santos; Suetonio expuso las Vidas de los Césares con mucha

26 Recientemente ha aparecido un interesante monográfico dedicado a "La canonización de 1622 y la santidad en el mundo moderno", con importantes aportaciones, en Anuario de Historia de la Iglesia (2020), 29, 15-289. 
más honradez e integridad que los católicos expusieron las vidas, no digo ya de los emperadores, sino de los mártires, confesores y vírgenes. Ellos, no callan los vicios, ni las sospechas de vicios en los filósofos y emperadores honrados; en cambio, en los depravados muestran incluso ciertos indicios de virtud. Por el contrario, los nuestros -en su mayoría- o se dejan llevar por sus preferencias, o fabulan también a sus anchas de tal manera, que no solo me avergüenzo de ellos, en realidad también me repelen, pues entiendo que no aportan nada de utilidad a la Iglesia de Cristo, y sí mucho de perjuicio ${ }^{27}$.

Juan Belda Plans señala, como ejemplo de la gran exigencia crítica que inspira De los lugares teológicos, que en esta obra podamos observar un evidente anticipo al tratamiento ilustrado de la hagiografía, fruto y evolución del espíritu de Trento ante las críticas protestantes sobre la figura del santo. Creemos que son de una gran importancia, en abundamiento a este espíritu crítico que dimana de los nuevos tiempos que va fraguando el Concilio, el consejo de Cano cuando sostiene

que vale la pena advertir al teólogo que no crea sin más que todas las cosas escritas por varones eminentes son perfectas en todo, pues alguna vez también caen, y como dijo aquel ceden a la carga, y son complacientes con el capricho de sus inteligencias, así como también hacen concesiones al vulgo con cierta frecuencia [...]; ni siempre están atentos, o a veces se cansan, hasta el punto de que Demóstenes hizo dormir a Cicerón, y a Horacio le sucedió algo parecido una vez con el mismo Homero. Pues son grandes, sin embargo son hombres ${ }^{28}$.

En la última sesión del Concilio de Trento, la número XXV, entre otras cuestiones (decreto sobre el purgatorio, reforma de las órdenes monásticas), se trató de la veneración de los santos y reliquias en el sentido de ordenar a los obispos que velasen, al predicar la palabra, por el auténtico sentido doctrinal de la Iglesia en relación a las reliquias y al respeto que merecen, al tiempo que el decreto defendía el dar culto a los santos y rechazaba, por impía, su incapacidad de intercesión ante Dios, como se propugnaba desde la teología de la Reforma.

Es importante destacar que de la lectura de algunos elementos de este importante decreto se desprenden, entre otros aspectos que ahora no nos ocupan, la condena de la superstición tanto en la veneración de los santos como en el

27 Melchor Cano, "La autoridad de la Historia humana", De Locis theologicis, ed. de Juan Belda Plans, (Madrid: BAC, MMVI) 645.

28 Citado por Juan Belda en La Escuela de Salamanca y la renovación de la teología en el siglo $X V I$ (Madrid: BAC, MM), 307. 
culto a las reliquias, que tantas pasiones había levantado en la controversia religiosa. Además, y en esta línea, el Concilio preceptúa un mayor rigor en el reconocimiento tanto de milagros como de reliquias, y también en la aprobación de nuevos milagros:

Destiérrese absolutamente toda superstición en la invocación de los santos, en la veneración de las reliquias y en el sagrado uso de las imágenes; ahuyéntese toda ganancia sórdida; evítese en fin la torpeza; de manera que no se pinten ni adornen las imágenes con hermosura escandalosa; ni abusen los hombres de las fiestas de los santos; ni de las visitas de las reliquias [...] Tampoco se han de admitir nuevos milagros, ni adoptar nuevas reliquias, a no reconocerlas y aprobarlas el mismo obispo ${ }^{29}$

Ni qué decir tiene que el Concilio explicita una idea que había sido común en la España de la primera mitad del Quinientos, y posteriormente, por lo que hace a la represión de la superstición, como prueba la obra de Pedro Ciruelo, Reprobación de las supersticiones y hechicerías (Guillermo de Millis, Medina del Campo, 1551).

Pero todo cuanto acabamos de exponer hasta aquí responde a un hecho incuestionable que se halla íntimamente unido a toda creación humana ya que, no hay que olvidar que la hagiografía en cuanto género, o 'modo de narrar unos supuestos hechos portentosos', lo es. De ahí que tengamos que tener en cuenta que tanto el concepto de santidad, como la narración de los hechos atribuidos a los santos que entraña la hagiografía no tuvieron unos contornos inmutables y fueron evolucionando al compás de los tiempos. Del mismo modo que se produce, como es ampliamente conocido, la decadencia de los libros de caballerías que corre a la par de la de las distintas ediciones de la Flos sanctorum. Debemos a fray Luis de Granada, en el más literario de los catecismos escritos en español, la Introducción del Símbolo de la Fe (1583-1585), texto contemporáneo a los que nos ocupan, su conocido contraste entre las historias fabulosas de la ficción caballeresca y las vidas de los mártires y santos, a las que considera "caballerías verídicas" y, en consecuencia, ejemplos de la heroicidad auténtica, en la línea del rigor crítico que reclamaba el Concilio ${ }^{30}$.

29 Sacrosanto Concilio de Trento, sesión XXV, 331-332.

30 Granada, en apoyo de su exposición doctrinal de la fe católica, defenderá que "Procuré acompañar esta doctrina con algunas historias y vidas de santos, traídas a sus propósitos y estas las más suaves que yo hallé, y más auténticas. Porque como la historia sea cosa muy apacible, quise recrear y cebar al cristiano lector con estos bocados tan suaves, para que de mejor gana se ocupase en la lición desta escritura, ya dejase las otras fabulosas y dañosas" (Luis de Granada, Introducción del Símbolo de la Fe, edición de José María Balcells, Madrid: Cátedra, 1989, 111). 
Estos nuevos tiempos en la percepción y tratamiento de la figura del santo, de los que se hace evidente eco Luis de León al presentar a Teresa de Jesús, responden, como vemos, en buena medida a la manera que demandaba Trento, como contrapunto, como ya hemos dicho, al pensamiento reformado que negaba su capacidad de mediación. Como sostiene Teófanes Egido:

Como fondo de todo se proyectaba la exaltación de los santos, entre otros motivos permanentes y anteriores, porque la reforma protestante los negaba en sus capacidades intercesoras, en su culto, en sus reliquias, en sus representaciones iconográficas, dimensiones todas cordiales y reafirmadas en Trento. Con efecto inmediato, la hagiografía cumplió con la doble función de satisfacer la demanda creciente de vidas de santos con los atributos contrarreformistas requeridas por Roma y con las cualidades extraordinarias, heroicas, taumatúrgicas, es decir, maravillosas, exigidas por las mentalidades colectivas, connaturalizadas con la presencia de los poderes divinos en la tierra aunque sólo fuera para luchar con los agentes del otro poder, también connaturalizado y no menos presente, de los agentes del demonio ${ }^{31}$.

En este sentido, nos recuerda este estudioso que el año 1588, el mismo en el que Luis de León edita las obras de Teresa de Jesús, Sixto V crea la Congregación de Ritos, con el firme deseo de aplicar el espíritu tridentino en favor del poder de Roma, centralización que aumentará considerablemente durante el pontificado de Urbano VIII ${ }^{32}$.

También es importante señalar como, a partir de Trento, progresivamente tanto la predicación como las vidas de santos se van adecuando, tanto al patrón que se establece para tratar al santo como a que este difundirá, en gran medida, la visión dogmática y de costumbres que establece el Concilio. Y esta influencia, que tanto vemos en las diversas artes figurativas, tendrá también su importante presencia entre el posible paralelismo que algunos estudiosos establecen entre géneros tan importantes como la novela picaresca y el relato hagiográfico, según han puesto de relieve investigadores, en el caso de Mateo Alemán, como Scham (2006), Gómez Canseco (2012) o Vitse (2014: 54-61), y de un modo muy particular, Henri Guerreiro en la edición póstuma que se espera de su tesis de estado,

31 "Hagiografía y estereotipos de santidad contrarreformista (La manipulación de san Juan de la Cruz)”, Cuadernos de Historia Moderna(2000) 25, monográfico: 61-85, 68.

32 "Hagiografía y estereotipos de santidad contrarreformista...", 68. 
en la que defiende el carácter contrarreformista de Alemán en la obra que este dedica a San Antonio (2014: 58) ${ }^{33}$.

\section{FINAL}

Luis de León, como hemos visto en los paratextos de su carta dedicatoria a la primera edición de las obras de Teresa de Jesús, y en la posterior Apología de la edición siguiente, publicada póstumamente en Roma en 1610, defiende su ortodoxia con la elegancia que distingue a su prosa, dominada por la sobriedad y claridad expositiva que realza con fuerza la intención hagiográfica con la que pretende persuadir al lector de las virtudes de Teresa, tanto en sus obras como en la reforma reflejada en sus carmelitas descalzas, al tiempo que argumenta en contra de quienes no cejaban en intentar oscurecer su obra con multitud de reparos infundados.

Todo ello se fundamenta en la conjunción de la fe y las obras que se proyecta en sus libros y en los testigos vivos de su obra reformadora, que son sus hijas de religión, ejemplo del valor que otorga Trento al estado célibe, reconocido por el Concilio como superior en perfección.

Fray Luis es muy consciente que Teresa de Jesús ha comenzado un nuevo tiempo histórico con su ingente labor reformadora y la impronta imperecedera de su espiritualidad, al compás también de los nuevos tiempos de Trento que exigen otras visiones de la santidad, como la que traza en estas dos cartas que nos ha legado y que reflejan la influencia del antiguo profesor del maestro León, Melchor Cano, expresada en sus importantes De los lugares teológicos, al tiempo que anticipan el planteamiento crítico que veremos, ya a partir del siglo XVII, en los bolandistas, en sus Actas Sanctorum, o en Jean Mabillon.

33 Michael Scham, "Guzmán de Alfarache in light of San Antonio de Padua: another look at Alemán's "Cosmovisión"”, Bulletin of Spanish Studies, 83, (2006): 175-186. Luis Gómez Canseco, "Estudio", en Mateo Alemán, Guzmán de Alfarache, (Madrid: Real Academia Española, 2012), 761929. Marc Vitse, "Introducción", en Mateo Alemán, San Antonio de Padua, en Henri Guerreiro y Marc Vitse (eds.), en Pedro M. Piñeiro Ramírez y Katharina Niemeyer (dirs.), La obra completa, 2, (Madrid/Frankfurt: Iberoamericana/Vervuert, 2014) 19-91. 


\section{REFERENCIAS BIBLIOGRÁFICAS}

Arredondo, María, Piere Soledad, Civil y Michel Moner (coords). Paratextos en la literatura española (siglos XV-XVIII). Madrid: Casa de Velázquez, 2009.

Bataillon, Marcel. Erasmo y España: Estudios sobre la historia espiritual del siglo XVI. Madrid: Fondo de Cultura Económica, 1986.

Belda, Juan. La Escuela de Salamanca y la renovación de la teología en el siglo XVI. Madrid: Biblioteca de Autores Cristianos, 2000.

Beltrán de Heredia, Vicente. "Un grupo de visionarios y pseudoprofetas durante los últimos años de Felipe II". Revista Española de Teología 8 (1947): 373 397.

Beltrán de Heredia, Vicente. "Un grupo de visionarios y psudoprofetas durante los últimos años de Felipe II y repercusión de ello sobre la memoria de Santa Teresa". Revista Española de Teología 8 (1947): 483-534.

Cano, Melchor. De locis theologicis. Edición de Juan Belda Plans. Madrid: Biblioteca de Autores Cristianos, 2006.

Ciruelo, Pedro. Reprobación de las supersticiones y hechicerías. Medina del Campo: Guillermo de Millis, 1551.

Díaz Martín, José Manuel. "De los Libros de la Madre Teresa a La perfecta casada. La intimidad entre Teresa de Jesús y Luis de León”. Bulletin of Hispanic Studies 93, n. 9 (2016): 949-962.

Egido, Teófanes. "Hagiografía y estereotipos de santidad contrarreformista (La manipulación de san Juan de la Cruz)". Cuadernos de Historia Moderna (2000) 25, monográfico: 61-85.

El Sacrosanto y Ecuménico Concilio de Trento. Barcelona: Ramón Indar, 1847.

Gómez Canseco, Luis. "Estudio". En Mateo Alemán, Guzmán de Alfarache, edición, estudio y notas de Luis Gómez Canseco, 761-929. Madrid: Real Academia Española, 2012.

Granada, Luis de. Introducción del Símbolo de la Fe. Edición de José María Balcells. Madrid: Cátedra, 1989.

Jesús, Teresa de. Libro de la vida, edición, estudio y notas de Fidel Sebastián Mediavilla. Madrid: Real Academia, 2014.

Jesús, Tomás de. Suma y compendio de los grados de oración. Roma: Iacomo Mascardo, 1610.

Jesús, Tomás de. Suma y compendio de los grados de oración. Estudio introductorio y edición de Silvano Giordano. Madrid: Ediciones Carmelitanas, 2011.

Lazcano, Rafael. "Fray Luis de León, editor y biógrafo de Teresa de Jesús (1515-1582)". Analecta Agustiniana 78 (2015): 77-116.

León, Fray Luis de. Obras Castellanas de Fray Luis de León, vol. I. Edición de Félix García. Madrid: Biblioteca de Autores Cristiano, 1957.

León, Fray Luis de. De los nombres de Cristo, edición de Cristóbal Cuevas. Madrid: Cátedra, 1977. 
León, Fray Luis de. De los nombres de Cristo. Edición, prólogo y notas de Javier San José Lera. Estudio preliminar de Fernando Lázaro Carreter. Barcelona: Círculo de Lectores, 2008.

Mancho Duque, María Jesús y Prieto, José María (eds.). Fray Luis de León, De la vida, muerte, virtudes y milagros de la Santa Madre Teresa de Jesús. Salamanca: Ediciones Universidad, 2015.

Porqueras, Alberto. El prólogo en el manierismo y barroco españoles. Madrid: CSIC, 1968.

Scham, Michael. "Guzmán de Alfarache in Light of San Antonio de Padua: another look at Alemán's 'Cosmovisión"”. Bulletin of Spanish Studies 83 (2006): 175-186.

Thompson, Colin P. "'Una elegancia desafeitada': Fray Luis de León y Teresa de Jesús". En San Juan de la Cruz and Fray Luis de León. A commemorative International Symposium, editado por M. Malcom Gaylord; F. Márquez Villanueva. 289-298. Newark (Delaware): Juan de la Cuesta, 1996.

VV.AA. "La canonización de 1622 y la santidad en el mundo moderno". Anuario de Historia de la Iglesia 29 (2020): 15-289.

Vega, Ángel Custodio. "Fray Luis de León (El orador)". En Historia General de las Literaturas Hispánicas II, Guillermo Díaz-Plaja (edi.),II, 590-595. Barcelona: Vergara, 1968.

Vitse, Marc. "Introducción". Mateo Alemán, San Antonio de Padua. Edición de Henri Guerreiro y Marc Vitse. Introducción de Marc Vitse (La obra completa, 2) 19-91. Madrid/Frankfurt: Iberoamericana/Vervuert, 2014.

Zabaleta, Juan de. El día de fiesta por la mañana y por la tarde. Edición de Cristóbal Cuevas. Madrid: Castalia, 1983.

Jaume Garau

Instituto de Estudios Hispánicos en la Modernidad (IEHM) Universitat de les Illes Balears Edificio Ramón Llull Ctra. de Valldemossa, km. 7.5 Palma de Mallorca (España) https://orcid.org/0000-0001-9522-8478 